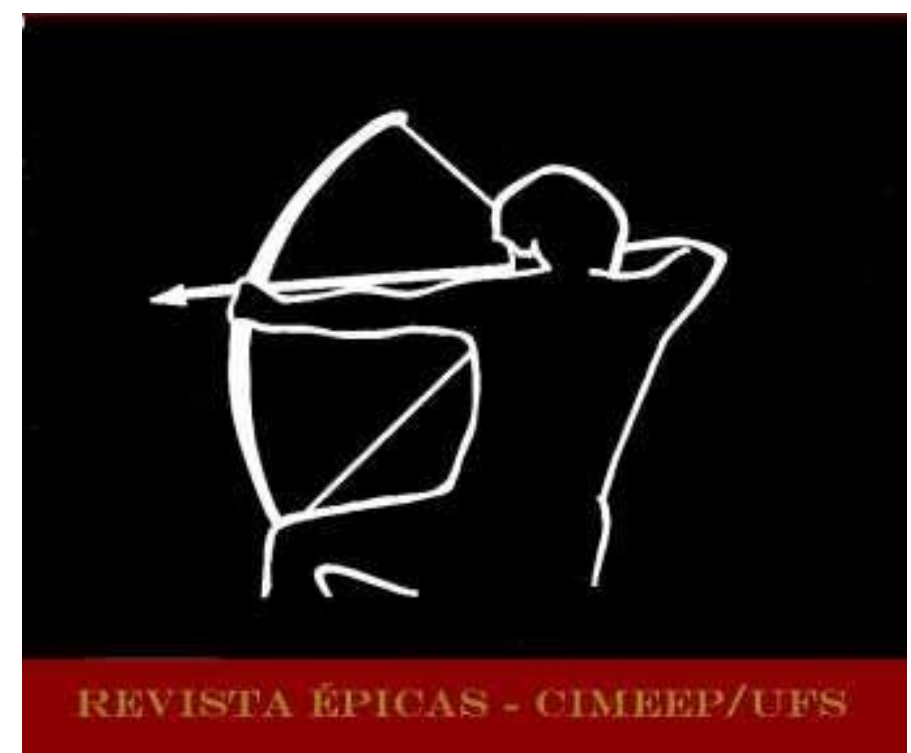

MATSUO, Esther Yuri; PAULA, Anna Beatriz. O épico na literatura ainu: Kuture Shirka. In: Revista Épicas. Ano 5, N. 10, Dez 21, p. 97-111. ISSN 2527-080-X.

DOI: http://dx.doi.org/10.47044/2527-080X.2021v10.97111

\title{
O ÉPICO NA LITERATURA AINU: KUTUNE SHIRKA
}

L'EPIC IN AINU LITERATURE: KUTUNE SHIRKA

\author{
Esther Yuri Matsuo \\ Universidade Federal de Sergipe - UFS ${ }^{1}$ \\ Anna Beatriz Paula ${ }^{2}$ \\ Universidade Federal do Paraná - UFPR
}

RESUMO: Os Ainu são povos indígenas originalmente das regiões norte do Japão (atual Hokkaido), mas também das ilhas Curilas (ou Kuriru) e no sul de Sakhalin (ou Karafuto); ademais, atualmente estão presentes em todo o território japonês e pelo mundo. Eles possuem línguas, crença e tradições próprias, sendo notória essas diversidades culturais. Da tradição oral temos narrativas com material épico riquíssimo que sintetiza muito bem suas crenças, costumes, identidade comunitária e territorial. A presente pesquisa teve como objeto de estudo uma literatura produzida no Japão pela etnia ainu e visou, principalmente, desfazer a construção de um único referencial épico naquele país, partindo da hipótese da possibilidade de pensar o épico na literatura ainu. Para atingir esses objetivos, foi necessário pesquisar a cultura e a história do povo ainu e, na sequência, investigar a sua literatura e a tipologia de seus textos para, então, definir um texto como base de investigação, o épico Kutune Shirka, de Kyosuke Kindaichi traduzido por Arthur Waley. Palavras-chave: Ainu; Matéria épica; Poema épico; Yukar; Kutune Shirka; Herói cultural ainu.

ABSTRACT: The Ainu are indigenous people originally from the northern regions of Japan (present-day Hokkaido), but also from the Kuril Islands (or Kuriru) and south of Sakhalin (or Karafuto); moreover, they are currently present throughout the Japanese territory and around the world. They have their own languages, beliefs and traditions, and these cultural diversities are notorious. From the oral tradition we have narratives with very rich epic material that very well synthesizes their beliefs, customs, community and territorial identity. This research had as object of study a literature produced in Japan by the Ainu ethnic group and aimed, mainly, at undoing the construction of a single epic

\footnotetext{
${ }^{1}$ Graduanda do curso de Relações Internacionais na Universidade Federal de Sergipe.

2 Professora Associada do curso de Letras da Universidade Federal do Paraná.
} 
reference in that country, based on the hypothesis of the possibility of thinking about the epic in the Ainu literature. To achieve these goals, it was necessary to research the culture and history of the Ainu people and, subsequently, investigate their literature and the typology of their texts to then define a text as the basis for investigation, the epic Kutune Shirka, by Kyosuke Kindaichi translated by Arthur Waley.

Keywords: Ainu; Epic material; Epic poem; Yukar; Kutune Shirka; Cultural Hero Ainu.

\section{Introdução}

Os Ainu são povos indígenas originários, principalmente, da região Ezo chi (atual Hokkaido no Japão) e de outras regiões como parte das ilhas Curilas e o sul de Sakhalim. Atualmente estão presentes em todo território japonês e em diferentes países compondo diásporas (DUBREUIL, 2007). Os primeiros registros escritos de suas narrativas foram no século XIX e XX, juntamente com o crescimento do movimento ativista político pelos direitos ainu no Japão, com a transcrição das histórias orais como uma das formas de preservação da memória e valorização da identidade ainu (HUDSON, et al, 2014). Contudo, apesar desse aumento de visibilidade para essas literaturas, como parte também da literatura japonesa, ainda são escassos os estudos - notadamente no "Ocidente" - voltados para o épico ainu. De fato, existe certa dificuldade no reconhecimento de suas obras como integrante do gênero épico, parte disso advém da falta de reconhecimento das tradições desses povos, situação que gerou, por muito tempo, a classificação dos yukar, textos épicos ainu, como apenas canções, como comentado por Howell (1951):

Why others have not recognized epic forms among the Ainu is perhaps easily explained. Relatively little field work has been done on the Ainu; Kindaichi usually wrote in Japanese; Batchelor is the primary non-Japanese source. Had Batchelor considered equal in importance to the content of a given of lore the method of its delivery, it is probable he would never have sloughed off yukara simply as "songs". (HOWEL, 1951, p. 361).

À vista disso, a presente pesquisa, que teve como objeto de estudo a literatura produzida no Japão pela etnia indígena ainu, visou, principalmente, desfazer a construção de um único referencial épico naquele país. Partindo-se da hipótese da possibilidade de pensar o épico na literatura ainu, este estudo procurou verificar se e como alguns de seus textos - oriundos de uma tradição oral - apresentariam características do gênero épico. Para atingir esses objetivos, foi necessário pesquisar a cultura e a história dos povos Ainu e, na sequência, investigar a sua literatura e a tipologia de seus textos para, então, definir um texto como base de investigação, qual seja, o épico Kutune Shirka, de Kyosuke Kindaichi, publicado originalmente em 1932 na língua japonesa, e em 2009 na língua inglesa, com a tradução de Arthur Waley, na obra de Kiyoku Miura Kutune Shirka: The Ainu Epic and Yukara: Epos of the Ainus, Study and Translation of Kamuy-Yukara".

Tendo consciência de nossas fronteiras analíticas e interpretativas sobre a literatura épica Ainu, procuramos priorizar autores e autoras que ou são ainu ou são referência nesses estudos - dando preferência àqueles com base pós-colonial. Os principais nomes são Chiri Dubreuil (2007), pesquisador e ativista japonês ainu, que possui diversos trabalhos acadêmicos e artísticos de reflexões profundas sobre a história, cultura e identidade contemporânea ainu; e Minako Sakata (2011), cujo artigo "Possibilities of Reality, Variety of Versions: The Historical Consciousness of Ainu Folktales" (sem tradução para o português) é uma referência para diversos trabalhos dentro dessa temática, sobretudo sobre os Hokkaido ainu, pois traz nessa análise a 
perspectiva histórica através das narrativas orais, principalmente no que concerne à relação entre os wajin e ainu. As pesquisas de Ann-Elise Lewallen, Sarah Strong (2011), Marcia Namekata e Luana Silva (2019), Richard Howell (1951), Minako Sakata e Donald Philippi (1979) trouxeram significativas colaborações em relação à literatura ainu, assim como os estudos de Christina Ramalho e Waldemar Pereira (2014) para o estudo da poesia épica.

\section{Ainu Studies e literatura ainu}

O olhar do "Ocidente" sobre o "Oriente" foi construído a partir de uma perspectiva eurocêntrica conforme denunciou o pesquisador Edward Said no clássico Orientalismo (1978). Nessa obra, Said defende que a perspectiva eurocêntrica gerou uma percepção simplificada, generalista e totalizante das culturas "orientais". Disso decorre o grande desconhecimento das diferentes culturas que existem nos igualmente diversos países que compõem o Oriente. São diferentes culturas que se expressam numa diversidade de línguas, hábitos, etnias, religiões e literaturas, por vezes dentro de um mesmo país. Tendo em vista esses processos, ressalta-se o discurso homogeneizante que interfere duplamente sobre o Japão, externamente, o país está incluído nessa construção eurocêntrica do Oriente por parte do Ocidente nos moldes criticados por Said; internamente, ocorre a construção do nacional, em processos de assimilação de povos originários e minorias étnicas, processo inerente ao projeto de construção de uma sociedade japonesa, a exemplo do que houve com os Ainu (HUDSON et al., 2014). Esse projeto de nação se deu, portanto, de forma excludente e homogeneizante, visto que ao apontar os Ainu como integrantes do território japonês, estes eram marginalizados e discriminados sócio-economicamente sob a égide de "ex-nativo" (HARRISON, 2007). Vale ressaltar que outros grupos minoritários sofreram semelhante exclusão e, diferentemente dos ainu, seguem sem reconhecimento oficial como grupos étnicos distintos.

As disputas territoriais entre Rússia e Japão pelas "Terras do Norte" somaram-se ao projeto político de assimilação dos Ainu a uma única identidade nacional imposta aos Ainu que se viram forçados a renegar suas diferenças internas, culturais e linguísticas (HARRISON, 2007). Com isso muitos foram coagidos a deixar seus lares e terra ancestral, sobretudo distintas das comunidades de Sakhalin e ilhas Curilas, para migrarem a Hokkaido. Foi uma política legitimada pela Lei de Proteção aos Ex-Aborígenes de Hokkaido de 1899, a mesma que os declarava "ex-nativos" (HARRISON, 2007). Como bem sintetiza Caprio (2001 apud Harrison, 2007, p. 8 e 9): "In the context of Indigenous peoples' history it is also important to keep in mind that the act of 'nation-building...is an act of colonization"'. Esses processos não se deram somente no campo da práxis, mas foram, sobretudo, no âmbito acadêmico com produções de conhecimento que tinham como objetivos legitimar as políticas colonialistas e a representação estereotipada dos Ainu. Foi a partir do reconhecimento e da crítica a essa epistemologia e política colonialistas que surgiu um movimento - protagonizado pelas distintas comunidades Ainu contemporâneas - de reconstrução do conhecimento sobre eles e suas narrativas (HUDSON, et al, 2014). As lutas e movimentos indígenas Ainu reivindicam não somente mudanças nas formas como são ainda retratados nos livros de História (DUBREUIL, 2007), mas também reivindicam 
direitos para "equal participation in the political, social and economic life of Japan" (SIDDLE, 2010, p. 447) e para tal, inicialmente, foi preciso o seu reconhecimento como população indígena pelo Governo Japonês para, com isso, elaborar uma pauta de reparação histórica. O reconhecimento Legal do Governo Japonês dos Ainu contemporâneos como minoria étnica ocorreu somente em $1997^{3}$, com a "Lei de Incentivo à Cultura Ainu e à Difusão e Esclarecimento da Tradição Ainu" que anulou a antiga Lei de Proteção aos Ex-Aborígenes de Hokkaido de 1899. Contudo, segundo Dubreil, essas mudanças formais político-legais se mostraram ineficientes na reparação histórica aos Ainu contemporâneos, pois, além de não reconhecer em sua totalidade a longa história de discriminação e colonização sofrida por aquela população, a Lei de 1997 reduziu os esforços para resoluções rasas. Segundo ele, "There are no educational grants, and no incentives to move Ainu people out of poverty" (DUBREUIL, 2007). Esse reconhecimento foi conquistado após o movimento ativista Ainu se filiar ao movimento indígena global, conquistando apoio de outros movimentos indígenas e visibilidade pela ONU (MASON, 2012). Isso resultou numa resolução promulgada numa Assembléia Geral da ONU em 2007 (HUDSON et al., 2014), representando uma mudança conjuntural significativa, sobretudo, na postura do Governo Japonês em relação às distintas comunidades Ainu contemporâneas. Contudo, houve poucas ações na agenda governamental japonesa para reparação histórica, especialmente no que concerne à demarcação de terras originárias aos Ainu.

Em termos acadêmicos, uma significativa mudança ocorreu em decorrência dessa mudança de perspectiva sócio-histórica do povo Ainu. Segundo os diversos autores e autoras que compõem o livro Beyond Ainu Studies: Changing academic and public perspective (2014) - com destaque para Uzawa Kanako, Mark K. Watson, Ann-Elise Lewallen, Mark J. Hudson e David L. Howell -, os Ainu Studies acompanharam as mudanças na agenda e relação do Governo Japonês com as distintas comunidades Ainu. Originalmente - no século XIX - o Ainu Studies era um "umbrella term" (HUDSON et al., 2014, p. 2), isto é, todo estudo, tanto nacional quanto internacional, sobre os Ainu tinham como padrão a objetificação do indivíduo Ainu sob uma única visão colonialista homogeneizante autorizada pelo Estado Japonês com representações históricas, antropológicas, raciais, culturais e linguísticas vinculadas a esse interesse político estatal ${ }^{4}$. Contudo, recentemente com os movimentos ativistas indígenas protagonizados pelos Ainu, a partir do século XX, adotou-se uma percepção crítica a essa epistemologia e estrutura colonialista (HUDSON et al., 2014), sobretudo, com reivindicações de direitos para "equal participation in the political, social and economic life of Japan" (SIDDLE, 2010, p.447). Com isso, surgiram inúmeras pesquisas sobre a cultura e literatura Ainu partindo de visões pós-colonialistas, rejeitando totalmente diversas concepções evolucionistas e caricatas

\footnotetext{
${ }^{3}$ Inicialmente houve um apelo, a partir da Associação Ainu de Hokkaido, para uma Lei que garantisse a reparação histórica com direitos políticos, civis e econômicos, expressados em cinco cláusulas, contudo, somente uma foi atendida pelo Governo Japonês resultando nessa Lei de 1997 (DUBREUIL, 2007).

${ }^{4}$ Não sendo uma dinâmica somente interna, mas reiterada na literatura global, como bem demonstra Harrison (2007): "In some cases the literature has taken on the global trend of moving from a view of the Native as 'savage' to one as a 'noble savage.' That is, they have moved from being "backward" and in need of civilization to survive to a position that has romanticised them and suggests that they possess something valuable to offer 'modern' peoples spiritually, medically, environmentally and/or theoretically" (p.28).
} 
sobre os Ainu 5 (HUDSON et al., 2014). De maneira que, Hudson, Lewallen e Watson (2014) apontam para polêmica em torno do Ainu Studies, pois carrega consigo o histórico vinculado a esses processos coercitivos de assimilação, isto é, imposição de uma única identidade nacional japonesa, e uma tradição de referências de "research positioning of scientific authority vis-à-is Ainu individuals who became research objects" (HUDSON et al., 2014, p. 2). Assim, esses pesquisadores, propõem que os atuais estudos sobre os Ainu, podem ser reconhecidos como "beyond Ainu Studies", ou seja, algo como pós-Ainu Studies, uma vez que estes valorizam a produção crítica acadêmica dos próprios Ainu (HUDSON et al., 2014).

A partir desse movimento, derivaram-se inúmeras produções e transcrições literárias como estratégias de reafirmação cultural e sobrevivência histórica (BUGAEVA, 2016). Kindaichi Kyôsuke (18821971), Chiri Mashiho (1909-1961), Imekanu (também conhecida pelo seu nome japonês, Kannari Matsu) (1875-1961), Chiri Yukie (1903-1922) e Kubodera Itsuhiko (1902-1971) foram figuras importantes desse processo, contribuindo no registro escrito de diversas obras épicas, sendo uma delas Kutune Shirka, formalizado por Kindaichi e Kannari. A partir dessas figuras, houve uma revolução nos Ainu Studies, sobretudo nos campos linguísticos e literários, porque oportunizou-se o surgimento de muitas pesquisas em contextos locais e internacionais, com materiais primários vindos pela diversidade narrativa e linguísticas de distintas comunidades Ainu. Contudo, ainda há pouca expressividade quantitativa desses estudos sob a perspectiva pós-colonial devido à natural resistência de abordagens orientalistas que perpetuam as concepções colonialistas que invisibilizam essas narrativas ${ }^{6}$, quanto por essas mudanças nos Ainu Studies serem recentes, do século XIX em diante, de maneira que ainda são estudos iniciais com pouca visibilidade.

Ressaltamos que, para fins desta presente pesquisa, baseamo-nos nesta concepção pós-colonialista para compreender o épico Ainu, tendo selecionado a obra Kutune Shirka, devido à sua relevância já apresentada anteriormente. O objetivo principal é compreender a matéria épica - elemento sui generis ao épico (RAMALHO, 2017) - presente na obra épica selecionada, investigando, para isso, a cultura e a História Ainu.

\section{Terminologias e especificidades épicas ainu}

Assim, para a compreensão dessas literaturas, sobretudo as épicas, percebemos a necessidade de ter o conhecimento prévio de algumas terminologias fundamentais, a saber: ainu, moshir e kamui.

\footnotetext{
5 “With American zoologist Edward Morse's introduction of Darwin's theory of evolution to Japanese students during the 1870s and the availability from the 1880s of translations of Herbert Spencer's writings on social evolutionism, differences in Ainu cultural practice and perceived evolutionary backwardness compared to the Japanese populace were integrated with pre-existing ideas linking social inferiority to bodily difference, generating local discourses on race." (HUDSON et al., 2014, p.3)

${ }^{6}$ Segundo Howell (1951), estudiosos como Batchelor não reconhecem essas literaturas como épicas, pois não levaram em consideração as tradições daquela comunidade no método de avaliação classificatória, levando os yukar a serem compreendidos como apenas canções. Como revela no trecho: "Why others have not recognized epic forms among the Ainu is perhaps easily explained. Relatively little field work has been done on the Ainu; Kindaichi usually wrote in Japanese; Batchelor is the primary nonJapanese source. Had Batchelor considered equal in importance to the content of a given bit of lore the method of its delivery, it is probable he would content have sloughed off yukara simply as 'songs'." (HOWELL, 1951, p.361)
} 
A tradução literal de "ainu" seria "ser humano", como bem demonstra Hashine (1977, p.39, apud NAMEKATA e SILVA, 2019, p. 131): “Ainu significa 'ser humano', mas não significa 'todos os seres humanos'. [...] Consequentemente, ainu significa um ser humano digno de respeito" que tem, originalmente, como oposto o kamui (um corpo espiritual) e não wenpo ${ }^{7}$ (um ser humano mal-intencionado ou "mal"). (NAMEKATA e SILVA, 2019).

Moshir ou moshiri refere-se à ideia de "espaço ou terra", normalmente sendo utilizada como sufixo (NAMEKATA e SILVA, 2019) (PHILIPPI, 1979). Kamui moshir e Ainu moshir representam "planos" diferentes, em que aquele significa "terra dos espíritos Ainu", este indica a "terra dos seres humanos" e os Ainu tradicionais ainda possuem a crença de que os acontecimentos neste plano são influenciados pela relação dos seres deste com os seres daquele plano (espiritual), os kamui (DUBREUIL, 2007 p.6). Já os yaun moshir, samoro moshiri e rep-un-moshiri são lugares dentro do ainu-moshir, de modo que representam a geografia em que estão inseridos. Yaun moshir ${ }^{8}$ tido como "continente" ou "país em terra" (PHILIPPI, 1979, p.4); e de acordo com Batchelos (1888, p.40), conforme comentado por Namekata e Silva (2019, p.131), samoro moshiri (ou shamon) e rep-un-moshiri indicam, respectivamente, ilha e ilha vizinha sendo esse último geralmente associado ao Japão.

A definição de kamui está intimamente ligada ao sagrado dos Ainu, pois esse termo faz referência ao divino e, portanto, pode ser entendido como "deuses" ou "espíritos divinos". Ademais na crença tradicional, os kamui se apresentam no ainu moshir como elementos da natureza como por exemplo: ursos, plantas, vento e baleias (DUBREUIL, 2007) que podem causar fenômenos atmosféricos ou naturais (STRONG, 2011), e ainda podem aparecer na literatura épica como "[...] Critically necessary tools, such as boats, made from local natural materials are also kamui and appear as first-person narrators of kamui yukar" (STRONG, 2011, p. 7). Contudo vale destacar que, segundo Dubreuil, a espiritualidade ainu não se encaixa no animismo:

The spiritual beliefs of the Ainu are complex, they do not fit the usual definition of animism, nor are they a form of Shinto. [...]. It is important to understand that we do not worship nature per se. All things in nature are spirits sent to Ainu mosir disguised as bears, trees, wind, etc. (DUBREUIL, 2007, p. 6).

Portanto, os Kamui são espíritos divinos que são entendidos na "forma animal" ou outro elemento da natureza, com cognição e vontades próprias: "It is important to note that the kamui are understood to have both a visible form as an animal or other natural phenomenon and an invisible spiritual existence with

\footnotetext{
7 A alteridade, principalmente nos textos épicos, normalmente era baseada na relação com a localidade, como por exemplo, a indicação em Kutune Shirka de um grupo não ainu como renpuku, isto é, habitante de ilhas, e de um grupo ainu como poiyaunpe que tem como referência os ainu do continente (PHILIPPI, 1979). Segundo Dubreuil (2007), não se tem muitos documentos demonstrando a dimensão do contato dos Ainu com outros povos antigamente, mas se sabe que é consideravelmente extenso devido ao comércio marítimo desenvolvido, e nessa se destaca também a itaomachip, canoa própria para essas viagens que os possibilita ir por grandes extensões. Além disso, por serem antigamente "um povo empreendedor do comércio marítimo" (DUBREUIL, 2007, p.12, tradução nossa) estavam habituados a negociare com outros povos, como por exemplo diferentes povos nas ilhas Curilas, em Sakhalin, Wajin - termo referente à etnia predominante no Japão, também se denominavam como Yamato (HARRISON, 2007), e os Ainu os chamaram inicialmente de shisam que significa vizinho, depois passaram a os chamar de shamo que significa colonizador (HARRISON, 2007) - e povos do nordeste da China.

8 Normalmente se atribuíam como habitantes do continente, yaun moshir, geralmente aparecendo a terminologia yaunkur (habitantes do continente ou da terra), principalmente, em textos épicos. (PHILIPPI, 1979).
} 
cognition, emotions, and agency similar to those of human beings" (STRONG, 2011, p. 7). De maneira que alguns kamui yukar (épicos míticos) eram antigamente utilizados para transmitir sabedoria e conhecimento dos próprios kamui para os Ainu (PHILIPPI, 1979), por isso o narrador estava geralmente em primeira pessoa, pois o próprio kamui se comunicava através da enunciadora, sendo esse o papel da xamã realizado normalmente por uma mulher ainu (STRONG, 2011). Além dessas terminologias essenciais muito presentes nas composições literárias e até no entendimento do contexto dessas narrativas, Strong (2011) e Philippi (1979) apresentam que é possível compreender a matéria épica e o fazer épico ainu a partir dos seguintes elementos: declamação da obra ${ }^{9}$; a linguagem empregada ${ }^{10}$, a forma de transcrição ${ }^{11}$ e o tema abordado. Da relação entre o tema e a forma de transcrição resultam outros gêneros, como: yukar ou sakorpe ${ }^{12}$, kamui yukar e uwepeker ou tuytak.

Yukar (ou sakorpe) são os épicos heróicos caracterizados por serem narrativas longas, contendo geralmente um "herói cultural", colocado como protagonista humano dotado de habilidades sobre-humanas chamado de kotan-kar-kamui, que significa um ser espiritual criado em ainu moshir (STRONG, 2011). O heroísmo, como seu tema central, contém construção complexa, variando a cada obra, sendo explicado melhor posteriormente. $\mathrm{Na}$ forma, configuram-se em versos e com refrões denominados de sakehe, marca da oralidade, e normalmente possui um narrador em primeira pessoa (NAMEKATA e SILVA, 2019).

Kamui yukar é considerado um das formas literárias-orais mais antigas na tradição ainu (WATANABE, 1994 apud MOODY, 2014); trata-se da transmissão de histórias com forte presença dos kamui, com a função de estabelecer conexão com o sagrado sendo recitado por um/a xamã (NAMEKATA e SILVA, 2019). Por objetivar a passagem oral dos ensinamentos e narrativas do sagrado, quando registrado em escrita, são mantidos os versos melodiosos que originalmente eram cantados (NAMEKATA e SILVA, 2019).

Uwepeker, ou tuytak, pode também ser chamado de uchashkuma em Sakhalin (NAMEKATA e SILVA, 2019) e, ao contrário dos anteriores, este gênero normalmente se apresenta em prosa, sendo mais informal, podendo ser traduzido como conto popular que contém histórias dos antigos, normalmente representando ensinamentos para os mais jovens (NAMEKATA e SILVA, 2019). Ainda, tinha como tema recorrente as aventuras dos Ainu comuns, havendo também narrativas sobre aventuras de não-ainu, caso dos shisam uwepeker ${ }^{13}$ (PHILIPPI, 1979). Por apresentar material épico, são, portanto, consideradas prosas épicas, como bem salienta Philippi: "we find many formulas in the mythic epics, and typical epic formulas are used even in the prose tales (uwepeker), which are narrated, not sung" (1979, p. 30).

Além dessas classificações, segundo as análises de Ohnuki-Tierney (1969 apud Namekata e Silva, 2019), que estudando a classificação narrativa dos Ainu, especificamente da costa noroeste de Sakhalin,

\footnotetext{
9 “[...]aqueles proferidos em uma voz normal falada sem cadência e aqueles com uma entrega controlada." (STRONG, 2011, p.6, tradução nossa).

10 Coloquial, refinada, ou poética (PHILIPPI, 1979).

${ }^{11}$ Se é prosaica ou em versos.

$12 \mathrm{Em}$ algumas comunidades em Sakhalin também é encontrado outras classificações, mas todas podendo ser correspondidas às características semelhantes, como "hawki, oyna (yukar/sakorpe) e upaskuma, tuiak (uwepeker)". (NAMEKATA e SILVA, 2019, p.133).

13 "shisam uwepeker are tales describing the adventures of Japanese" (PHILIPPI, 1979, p. 24)
} 
apontou para as diferenças terminológicas existentes devido a variações regionais. A exemplo das diferenças regionais em terminologias nas categorias literárias são hawki e oyna, que aparecem semelhantemente ao yukar com algumas diferenças (NAMEKATA e SILVA, 2019). Apesar de todas essas partirem das narrativas dos espíritos sagrados, a diferença estaria nos assuntos geralmente tratados e na regionalidade. Hawki usualmente pode tratar em seu conteúdo batalhas épicas, enquanto oyna não (NAMEKATA e SILVA, 2019, p.133), e o yukar se refere "[...] aos épicos divinos em verso [...]" (NAMEKATA e SILVA, 2019, p.136), e ainda segundo esses autores, o yukar é classificação predominantemente utilizada pelos Ainu de Hokkaido. Lembramos, portanto, que diversas obras não se encaixam perfeitamente nessas classificações, tendo características conjuntas ou dissonantes na forma ou conteúdo, e que a depender de quem recita e transcreva, uma obra pode mudar de gênero literário (SAKATA, 2011). Consequentemente, essas divisões e classificações nos ajudam a situar a obra estudada em forma, tema e função, porém permitem também a análise de especificidades, demandando um olhar amplo e específico do fazer literário dessas comunidades.

\section{Gênero épico e o épico ainu Kutune Shirka}

O gênero épico, apesar de muitos apontarem ser uma escrita morta na modernidade e pósmodernidade, está, pelo contrário, presente em diversas localidades e comunidades, sendo dele a expressão de suas identidades tanto geográficas quanto humanas e, principalmente, compondo uma identidade nacional (RAMALHO, 2017). E apesar de ser um conceito inicialmente ocidental europeu, é possível identificar o gênero épico com as particularidades de outras geografias e culturas, sendo ainda algo próprio de cada nação e sociedade que a produz. Ademais, Ramalho (2017), ao fazer análise sobre origem e essência do gênero épico, coloca que uma abordagem restrita a somente um local, momento histórico, comunidade e obra, torna-se um estudo de caso ou uma análise crítica histórico-literária, e não uma formulação teórica capaz, de fato, de fundamentar uma análise sobre o gênero, pois seria um conceito inadequado para dar conta das transformações das produções literárias através dos tempos e espaços. Logo, o que caracteriza uma obra como integrante ao gênero épico, é a matéria épica presente, que, como bem sintetizado por Ramalho (2017), deriva da fusão entre o mítico e o real. Ademais como bem complementa Oliveira:

Em suma, o processo que leva uma obra a se tornar um "épico" deve ser considerado como um evento social completo, que inclui, entre outros, interação com a audiência, música instrumental e gêneros sobrepostos. Seu potencial é imenso e ambicioso, tomando para si a tarefa de articular os aspectos sociais de uma cultura, das suas histórias de origem até ideais de comportamento, estrutura social, relação com o mundo natural e também com o sobrenatural (OLIVEIRA, 2013, p. 14).

Outrossim, vale salientar que o elemento sui generis ao gênero épico não é exatamente o mesmo nas distintas formas de composições épicas. Por exemplo, para uma obra ser considerada epopeia é necessário, no mínimo, "possuir a dupla instância de enunciação, derivada da forma em versos" (RAMALHO e PEREIRA, 2014, p.132), ou seja, uma obra pode ser épica, mas não ser uma epopeia mesmo havendo o discurso épico. É importante observar que Kutune Shirka pode ser classificado como um poema épico dada 
a matéria épica que a constitui, a construção do herói e ainda sua escrita em versos, contudo há divergências quanto à sua classificação como epopeia, visto que o sui generis à epopeia pode não ser encontrado a depender da versão da obra, e das contradições existentes em algumas versões, como bem menciona Howell:

There is a lengthy discussion of the Ainu epic language followed by rather distinct versions of a single yukara, the 'Kutune Shirka'. The first version is in 7,035 five-sylable lines, and is divided into nine sections, approximately one per battle. The other version is in but four sections, although it runs to 8,220 five-syllable lines (HOWEL, 1951, p. 364).

A compreensão e a análise sobre o épico numa literatura seguem não somente o contexto e características técnicas das composições, mas também sua recepção por parte da sociedade e da comunidade acadêmica como um épico. Diversos pesquisadores e autores como: Lewallen (2012), Strong (2011), Namekata e Silva (2019), Howell (1951), Sakata (2011) e Philippi (1979) defendem a concepção de que, sim, é perceptível o épico nessa literatura. Todos apresentam estudos derivados principalmente das discussões sobre a historicidade da tradição Ainu, mas também se baseiam principalmente na classificação feita pelos próprios Ainu ${ }^{14}$. Dentre as dificuldades no estudo dessas literaturas, destacam-se as mudanças no formato das obras, visto que tanto a prosa quanto os poemas vêm da tradição oral, e essa mudou drasticamente ao longo do tempo, de modo que é possível encontrar diversas versões da mesma obra, o que dificulta sua classificação e análise. A questão da tradução também é um obstáculo, pois a depender do tradutor o tipo de eu-lírico muda (MAJEWICZ, 1992), e até a interpretação de acontecimentos históricos pode ter sido alterada (SAKATA, 2011). E apesar de evidenciarem as problemáticas existentes na dependência dos gêneros literários no estudo das literaturas orais, é um consenso entre os estudiosos sobre a literatura e cultura Ainu, que o épico existe e resiste nessa comunidade, um exemplo disso é, como veremos, o yukar Kutune Shirka.

O Kutune Shirka possui diversas versões, com destaque para duas: a primeira versão, em 1913, de Nabesawa Wakarpa, ${ }^{15}$ sendo transcrita e publicada por Kindaichi Kyôsuke na língua japonesa, o "Itadori-maru no kyoku", mas sendo analisada por ele na obra "Ainu jojishi Itadori-maru no kyoku [Ainu epic Kutune Shirka]" em 1944; a segunda versão de Horobetsu, foi realizada por Imekanu (ou Kannari Matsu) (PHILIPPI, 1979), ambas sendo na língua japonesa. As versões nas quais nos baseamos para este estudo foram a de Arthur Waley ${ }^{16}$, que a traduziu para o inglês e que está contida na obra Kutune Shirka: The Ainu Epic and Yukara: Epos of the Ainu, Study and Translation of Kamuy-Yukara (MIURA, 2009) e a de Etenoa transcrito por Kubodera em 1993, analisada por Philippi (1979).

\footnotetext{
14 Respaldado nessas perspectivas pós-coloniais sobre os Ainu, Philippi (1979) defende a presença do épico na literatura ainu, apontando para os gêneros literários mais presentes e percebe o destaque do gênero épico nas produções ainu: "The lyric, the epic, and the ritual or ceremonial genres exist in abundance among the Ainu, but there is no evidence of any dramatic folklore among the Ainu. The epic genre is the one which has attained the greatest flowering among the Ainu. If one includes here all types of recited or sung narratives, the Ainu epic literature embraces a vast body of material, greatly overshadowing in its importance and its quantity the lyric and the ritual or ceremonial genres" (PHILIPPI, 1979, p. 22).

${ }^{15}$ Nabesawa Wakarpa era um Ainu ancião, e conhecedor de muitas histórias orais (MIURA, 2009).

${ }^{16}$ Arthur Waley (1889-1966) foi um orientalista responsável pela tradução de diversas obras literárias e poemas da China e Japão para a língua inglesa, com destaque, a sua tradução da obra japonesa Tale of Genji (DE GRUCHY, 1999).
} 
A história se passa num período anterior à indexação das terras originárias ainu pelo Japão, porém não se sabe quando exatamente se passa essa narrativa, visto que advém da tradição oral, passada de geração em geração (PHILIPPI, 1979) e que não há documentos suficientes que nos situe na temporalidade exata dos fatos. Essa imprecisão também ocorre quanto à localização exata dos acontecimentos nesse yukar. Contudo, visto que um dos temas abordados é a batalha entre poiyaunpe (ainu) e repunku, é possível situar geograficamente em Hokkaido, Curilas, Sakhalin ou Rebun, pois esses confrontos reais históricos ocorreram nesses locais, a incluir também o Norte da Ásia (PHILIPPI, 1979). Além disso, ainda segundo Philippi (1979, p. 40): "The epics locate the repunkur geographically along the northern coastline of Hokkaido facing the Okhotsk Sea, in the Kurile Islands, and on the island of Sakhalin (called Karapto in the epics)".

Já a história do Kutune Shirka na narrativa ocorre um homem repunkur de Ishkar anuncia uma disputa por uma lontra marinha dourada, oferecendo, como recompensa ao vencedor, a sua própria irmã juntamente com todas as suas riquezas. O evento é destinado apenas aos renpukur, mas o herói do povo poiyaunpe, Itadori, por vias indiretas e despretensiosas, toma conhecimento da disputa. O jovem chefe poiyaunpe não se interessa pelo evento, porém numa noite, os kamui o agitam não permitindo seu descanso e o carregam até Ishkar para encontrar a lontra marinha dourada. A captura é bem sucedida e Itadori leva o animal para sua casa, pois não ambicionava qualquer recompensa. O herói não percebe que a consequência desse ato será uma guerra entre sua comunidade poiyaunpe e a outra comunidade repunkur ${ }^{17}$. Afinal, Itadori teria infringido a tradição por participar da disputa destinada aos homens repunkur. O final da história é controverso, sendo modificado a cada versão escrita da obra. Na versão de Eteona, comentado por Philippi (1979), o desfecho é pacífico uma vez que Itadori se descobre poiyaunpe pelo lado paterno, e renpukur pelo lado materno, desconfigurando, assim, a infração cometida ao caçar a lontra marinha dourada:

Finally, the hero hears a rumor. On the opposite side of the bay, his enemies of old have come sailing up in a large fleet and are building village there. They say that they are unable to compete with Poiyaunpe and desire to cast their lot in with him and to fight on his side. They are preparing wine and treasures as gifts to present to him. Hearing this rumor, the hero laughs silently to himself and continues to do his carving, his eyes focused on a single spot. The hero Poiyaunpe thus gives his tacit consent to a merging of the yaunkur with the surviving remnants of their old enemies, the repunkur (PHILIPPI, 1979, p. 44).

Já na versão traduzida de Arthur Waley, a obra termina com a execução da bela jovem da comunidade repunkur pelo herói que assim procede por ter sido vitimado por um encantamento lançado sobre a jovem pela poderosa feiticeira, Sra. Malinger ${ }^{18}$. Diferentemente da versão de Eteona, a tradução de Waley oferece um desfecho violento e sangrento.

\section{A construção do herói cultural em Kutune Shirka}

\footnotetext{
${ }^{17}$ Os termos que designam os povos nas literaturas épicas ainu, referem-se à geografia na qual se inserem, poiyaunpe especificando um grupo yaunkur, isto é os ainu do continente, e renpuku um povo não ainu que vive em ilhas, e cuja principal atividade de subsistência era, possivelmente, a pesca e caça de animais marinhos (PHILIPPI, 1979).

${ }^{18}$ Esse nome foi denominado pelo tradutor, não correspondendo ao original.
} 
O herói presente nos épicos ainu são complexos e divergem nas suas construções a depender da obra. Segundo os estudos de Strong (2011) a construção desse "herói cultural" é feita de maneira a representar a ideal conduta de ética e valores justos, sendo um "herói puro" que se vê diante de confrontos entre humanos e espíritos malignos que os querem subjugar. Contudo, segundo os estudos de Donald L. Philippi sobre os épicos ainu (1979), pode-se notar um padrão geral sobre como é concebido esse herói cultural que se manifesta de forma ambígua, sendo ao mesmo tempo super-humano e bestial:

On the one hand, the culture hero is the ancestor of the human race, the originator of everything of value in human life, and the possessor of powers far superior to those of any of the gods in heaven or on earth. Here we see clearly the archaic concept of the superiority of human beings over gods. However, this same hero is depicted as being stupid, violent, and uncouth. In some accounts he is made to steal someone else's wife. In other cases he is unable to control his fury and, after victory over the harmful demons, proceeds to ravage the human homeland. This contradiction does not seem to strike the native audience as odd. The highest ideal of a hero for them apparently has nothing to do with right or wrong. The hero is great simply because he is great, and ethical considerations do not apply to him (PHILIPPI, 1979, p. 185).

Logo, essas análises divergem na razão pela qual esse herói é digno de admiração: para Strong (2011), um exemplo de virtude e conduta; e para Philippi (1979), um personagem para além da ética e moral. É possível verificar que os dois pesquisadores convergem, entretanto, em relação a esse herói guardar características de um ser humano na complexidade de suas emoções e escolhas, estando num espaço entre ainu (ser humano) e kamui. Para apresentar a construção do "herói cultural ainu" no yukar Kutune Shirka, baseamo-nos na perspectiva de Philippi (1979), visto que na sua formulação foi utilizado esse yukar como um dos fundamentos de seu estudo, sobretudo para demonstrar a relação entre ou yaunku e renpuku a partir do yukar.

Em Kutune Shirka, esse herói cultural é, sobretudo, intimamente ligado ao espaço a partir mesmo de sua própria moradia, local onde sua jornada tem início.

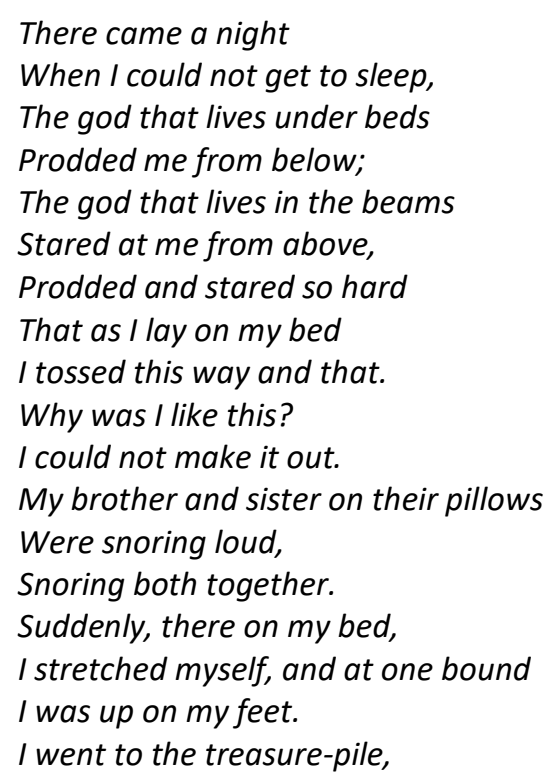




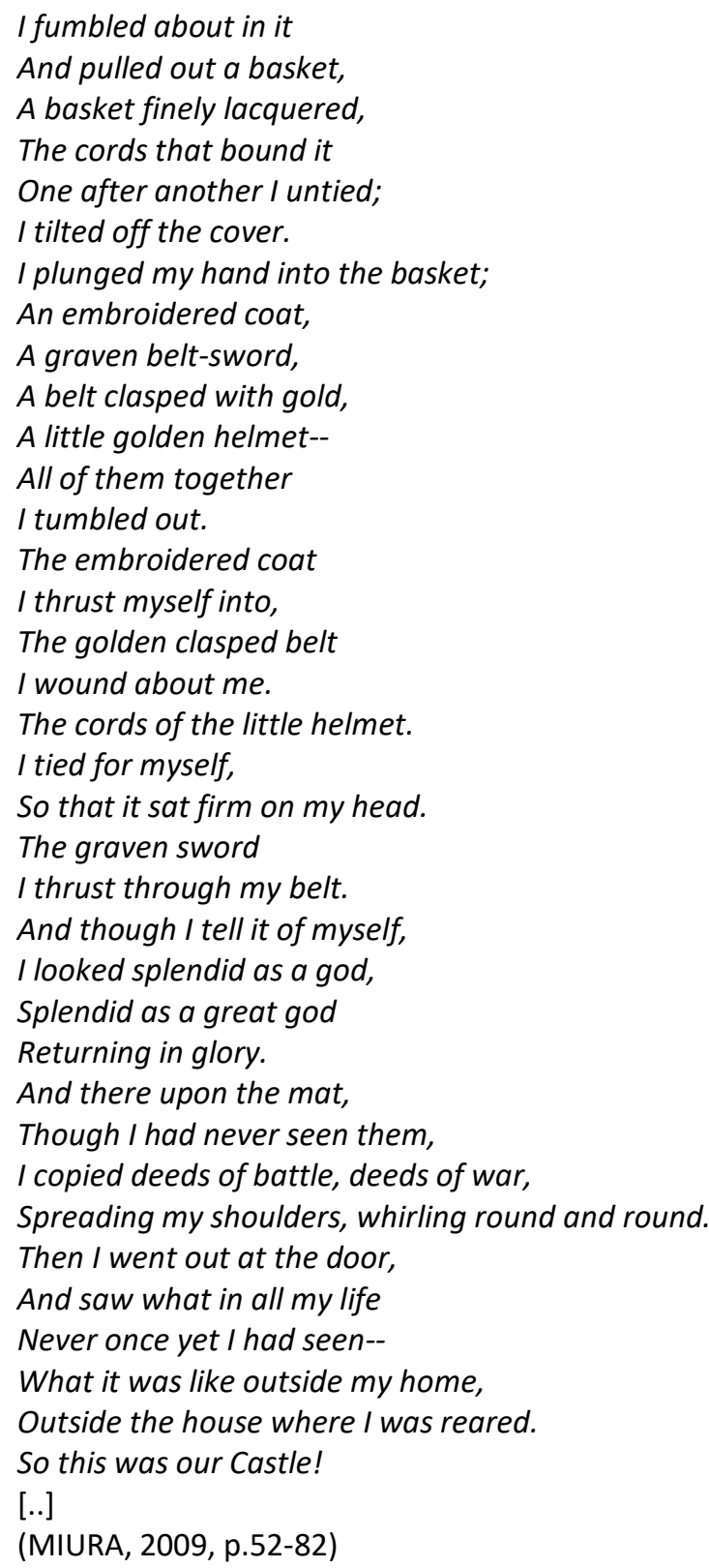

Ao longo dessa jornada heróica, esses diferentes espaços serão descritos como marcadores das regiões que os diferentes povos - poiyaunpe e renpuku - ocupam. Expressa-se assim, a divisão interna desse herói. Conforme a narrativa evolui, o herói percebe que as localidades e os dois diferentes povos se integram na história de sua família. Com isso, a integralidade do herói também é conquistada. E ao integrar suas diferentes partes/culturas, ele compreende que não há necessidade de exterminar seu inimigo e, numa atitude compassiva, encerra a guerra. Ambos os povos e suas geografias se integram na história da família deste herói, formando um todo. E o mar que antes separava, passa a ser o elemento que conecta e unifica essa experiência interna e externa do herói e sua comunidade. E vale ressaltar, ainda, que sua jornada heróica é acompanhada pelos kamui, que o guiam e auxiliam nos momentos necessários e críticos:

I followed down, when suddenly

Some god possessed me and from the ground I trod

A wind carried me high into the air;

High above the path to seaward. 
And brought me to a harbour,

Close to a harbour on the shore.

And coming from the sea

A pleasant breeze blew on me and the face of the sea

Was wrinkled like a reed-mat.

And on it the sea-birds

Tucking their heads under their tails,

Bobbing up their heads from under their tails

Called to one another

With sweet voices across the sea.

Over long stretches of sand

I strode, and as I went

The god that possessed me

Thundered in the sky above,

And swiftly along the shore-way

Hurried me to the village of Ishkar,

Near to Ishkar he carried me.

And the castle of Ishkar,

How beautifully it was built!

And under the white foam of the waves

(What they had said was true)

The golden sea-otter

Suddenly, like the glint of a sword,

Flashed above the breakers of the sea.

(MIURA, 2009, p.113 e 114)

Desse modo, mesmo nas diferentes versões com finais completamente opostos, a construção do

herói cultural que ao incorporar os poderes dos kamui, torna-se capaz de realizar qualquer feito, especialmente aqueles em que há forte apelo emocional, como se percebe no seguinte excerto:

The hero is resting after a battle, and his female relatives are just beginning to treat his wounds when, suddenly, he hears a god coming from the land of the repunkur. A voice cries out, bringing the following message: "I am the servant woman of Ukampeshka-un-mat, the younger sister of Ukampeshkaun-kur. When you were previously doing battle at Omanpesh, both Ukampeshka-unkur and his younger sister were to have gone to fight against you, but the younger sister secretly sympathized with you and refused to fight against you. She announced that she had a sudden stomachache and that she was unable to accompany her brother into battle. However, there being many potent wizardesses among the repunkur, it was discovered that Ukampeshka-un-mat was secretly in love with Poiyaunpe. Ukampeshka-un-mat was taken prisoner and is now being tortured in a place called Shisuye-Santa Kari-Santa." The servant woman begs the hero to go and rescue the lady, who is known by the nickname Nisap Tasum (Sudden Illness). The hero immediately forgets his pain, pushes aside the women, and goes out. Jumping into the water, he swims along through the ocean until he arrives on the sandy beach at Shisuye-Santa Kari-Santa. He extracts the many sharp points from his own body (he had been wounded with them in a previous battle) and prays to his companion spirits to restore him to his former bodily condition. His wounds are healed by revivifying winds which come blowing down (KUBODERA, apud PHILIPPI, 1979, p. 48).

Esse padrão de percepção sobre o herói como uma combinação de sublimes e terríveis capacidades, leva a compreensão da relação do herói ainu com a humanidade, ou seja a própria compreensão do que significa "ainu", conforme explicado anteriormente. 
Diante do estudo realizado e pensando num diálogo com a produção crítica ainu acessada, fica claro que só é possível pensar o épico na literatura ainu a partir do reconhecimento da cultura e da história desse povo, valorizando suas tradições como parte das diferentes culturas presentes no Japão. Embora muitos dos estudos literários japoneses ainda se fixem na única narrativa presente na composição do Estado-Nação, foi animador observar - a partir desta pesquisa - diversos estudos em diferentes localidades sobre as diversas literaturas Ainu - tanto na especificidade crítica, como no contexto de literatura indígena, quanto como parte, também, da literatura japonesa.

O Kutune Shirka, assim como outras obras literárias ainu são excelentes meios para a complexificação das narrativas dos Ainu e do Japão, sendo indispensável para o estudo da matéria épica dessa obra, o conhecimento sobre as próprias terminologias e classificações locais do épico e do herói cultural. Com isso cito Chimamanda Adichie: "quando rejeitamos a história única, quando percebemos que nunca existe uma história única sobre lugar nenhum, reavivemos uma espécie de paraíso" (2019, p.33). Com isso, vale a reflexão sobre quantas narrativas se perderam juntamente com as perdas humanas e saberes tradicionais oprimidos, concomitante aos processos históricos hegemônicos globais e locais que, até o momento presente, exercem influência sobre a divulgação da diversidade cultural e literária seja do Japão, ou de outros muitos países tanto no Oriente quanto no Ocidente.

\section{Referências bibliográficas}

ADICHIE, Chimamanda Ngozi. O perigo de uma história única. São Paulo: Companhia das Letras, 2019. BOWRA, C. M. Heroic Poetry. London: Macmillan and CO.LTD, 1952.

BUGAEVA, Anna. Toward New Horizons in Ainu Studies: Research Activities of the NINJAL-based Ainu Research Group. Tokyo University of Foreign Studies International Japanese Studies Report I 2015 International Symposium International Japanese Studies Dialogues, Interactions, Dynamics Internationalizing Japan Studies: Dialogues, Interactions, Dynamics, [s. I.], p. 122-136, 13 dez. 2016. Disponível em: https://www.academia.edu/download/51444562/5_12262016AB_ed_\%E3\%83\%96\%E3\%82\%AC\%E3\%82\% A8\%E3\%83\%AF-122-136.pdf. Acesso em: 30 Jul. 2021.

DE GRUCHY, J. W.. Orienting Arthur Waley : Japonisme, Orientalism and the creation of Japanese literature in English (T). University of British Columbia, 2000. Disponível em: https://dx.doi.org/10.14288/1.0099534. Acesso em: 30 Jul. 2021.

DUBREUIL, Chisato O. The Ainu and Their Culture: A Critical Twenty-First Century Assessment. The AsiaPacific Journal: Japan Focus, [s. I.], v. 5, ed. 11, 3 nov. 2007. Disponível em: https://apjjf.org/-Chisato-KittyDubreuil/2589/article.html. Acesso em: 15 Abr. 2021.

HARRISON, Scott. The Indigenous Ainu of Japan and the "Northern Territories" Dispute. 2007. $162 \mathrm{f}$. Thesis (Master of Arts in History) - University of Waterloo, Waterloo, Ontario, Canada, 2007. Disponível em: https://uwspace.uwaterloo.ca/bitstream/handle/10012/2765/Scott\%20Harrison_GSO_Thesis.pdf?sequenc e=1. Acesso em: 5 Abr. 2021.

HOWELL, Richard W. The Classification and Description of Ainu Folklore. The Journal of American Folklore, vol. 64, no. 254, 1951, pp. 361-369. Disponível em: www.jstor.org/stable/537004. Acesso em: 15 Abr. 2021.

HUDSON, Mark J, et al. Beyond Ainu studies : Changing academic and public perspectives. Univerisity of Hawaií Press: Honolulu, 2014. 
LEWALLEN, Ann-elise. Ainu Spirts Singing: Chiri Yukie and the Origins of the Ainu Shin'yoshu. Japanese Language and Literature, vol. 46, no. 1, 2012, pp. 47-52. Disponível em: www.jstor.org/stable/41442038. Acesso em: 11 Abr. 2021.

MAJEWICZ, Alfred F. Bronisław Piłsudski's heritage and Lithuania. Acta Orientalia Vilnensia, [s. I.], ed. 10, p. 63-96, Janeiro 2009. DOI 10.15388/AOV.2009.3670. Disponível em: https://www.researchgate.net/publication/331017000_Bronislaw_Pilsudski's_heritage_and_Lithuania. Acesso em: 15 Abr. 2021.

MASON, M. M.. Writing Ainu Out. In: Dominant Narratives of Colonial Hokkaido and Imperial Japan. Palgrave Macmillan, New York: 2012. Disponível em: https://doi.org/10.1057/9781137330888_3. Acesso em: 5 Abr. 2021

MIURA, KIYOKU. Kutune Shirka: The Ainu Epic and Yukara: Epos of the Ainus, Study and Translation of Kamuy-Yukara. Kindle edition, United States of America: Library of Alexandria, 2009.

MOODY, Joanna C.. The Ainu Speak of Famine: How Oral Traditions Reflect and Inform Historical Analysis of Changing Food Practices and Trade Relations in Early Modern Period Hokkaido (1603-1868). Honor Theses: SCARAB. 55, 2014. Disponível em: https://scarab.bates.edu/honorstheses/55/. Acesso em: 15 Abr. 2021.

NAMEKATA, Márcia Hitomi, SILVA, Luana Bueno B. C. da. O Divino nas Narrativas Ainu. Estudos Japoneses, [S. I.], n. 42, p. 129-143, 2019. doi: 10.11606/issn.2447-7125.v0i42p129-143. Disponível em: https://www.revistas.usp.br/ej/article/view/172450. Acesso em: 15 Abr. 2021.

OLIVEIRA, João Leonardo Cristino de. Heike Monogatari como exemplar do gênero épico e suas influências na cultura japonesa. 2013. 36 f. Monografia (Licenciatura em Língua e Literatura Japonesa) - Universidade de Brasília: Brasília, 2013. Disponível em: https://bdm.unb.br/handle/10483/5819. Acesso em: 30 Jul. 2021

PHILIPPI, Donald L. Songs of Gods, Songs of Humans: The Epic Tradition os the Ainu. Japan: Pricenton University and University of Tokyo, 1979.

RAMALHO, Christina Bielinski. A Cabeça calva de Deus, de Corsino Fortes: o epos de uma nação solar no cosmos da épica universal. 2 ed. Modificada. 1 ed. E-book, Natal: Lucgraf, 2017.

RAMALHO, Christina Bielinski, PEREIRA, Waldermar Valença. A Recepção teórica à poesia épica. Miguilim, v.3, n.1, Jan.-abr., Brasil: 2014.2 Disponível em: http://periodicos.urca.br/ojs/index.php/MigREN/article/view/650. Acesso em: 15 Abr. 2021.

SAKATA, Minako. Possibilities of Reality, Variety of Versions: The Historical Consciousness of Ainu Folktales. In: Oral Tradition. University of Missouri-Columbia. Center for Studies in Oral Tradition, Johns Hopkins University Press, v.26 n.1, p. 175-190, Janeiro, 2011. Disponível em: https://journal.oraltradition.org/wpcontent/uploads/files/articles/26i/08_26.1.pdf. Acesso em 25 Abr. 2021.

SAID, Edward W. Orientalismo: o Oriente como invenção do Ocidente. São Paulo: Companhia das Letras, 1990.

SIDDLE, Richard. The limits to citizenship in Japan: multiculturalism, indigenous rights and the Ainu. Citizenship Studies, [s. I.], $\quad$ v. $7, \quad$ p. $447-462, \quad 3$ jun. 2010. Disponível em:https://doi.org/10.1080/1362102032000134976. Acesso em: 30 jul. 2021.

STRONG, Sarah Mehlhop. Ainu spirits singing: the living world of Chiri Yukie's Ainu shin'yōshū. United States of America: University of Hawaií, 2011.

WALEY, Arthur. Kutune Shirka: The Ainu Epic. Botteghe Oscure, Rome, pp. 214-236, 1951. Disponível em: https://www.sacred-texts.com/shi/ainu/kutune.htm. Acesso em: 30 Jul. 2021 